EPOS, XIV (1998), págs. 363-379

\title{
LECTURA E INTERPRETACIÓN: EL RECEPTOR COMO INSTANCIA DEL DISCURSO EN LA NARRATIVA DE LA BAJA EDAD MEDIA
}

JAVIER VELLÓN LAHOZ

\section{RESUMEN}

El artículo trata sobre el proceso de ficcionalidad en la narrativa del siglo $X V$, para lo cual analiza las relaciones del texto con las nuevas condiciones de recepción, materializadas en la disposición de los lectores de la letra impresa hacia el hecho literario. De esta manera, las obras señalan implícitamente a la transformación de la textualidad en historia ficticia y a la función interpretativa del propio receptor.

El desarrollo y expansión de la sociedad burguesa a partir del siglo XIV contribuyó a generar nuevos modelos de vivencias urbanas en las que el libro, la lectura, la letra impresa - con tendencia a la ficción-ocupan un lugar de privilegio. Se trata de un fenómeno que alcanzará una notable extensión cuando la imprenta logre integrarse en los hábitos colectivos, transformando no sólo el aspecto material de la textualidad (al generalizar un producto concreto, distinto de la pieza manuscrita), sino también los medios de difusión, así como el propio concepto de lectura — sin olvidar que persiste la oralidad, en perfecta sintonía con la práctica individual y silen- 
te '- y la relación dialéctica entre las estrategias creativas y el acto de recepción.

Lo que se conoce como «epidemia lírica», entre los siglos XIV y XV, responde a un proceso general de la cosmovisión del mundo arraigada en las nuevas estructuras socio-económicas, cuyo foco catalizador es el emergente individualismo y su consecuencia primera: la conciencia personal como eje ordenador del mundo. Como síntoma de este cambio de mentalidad, se observa una singular revolución en el sistema del pensamiento medieval y, así, desde las postrimerías del siglo XIII, el tomismo sustituye al simbolismo metafísico, franqueando el paso al paradigma racionalista que interpreta al ser como la simbiosis armónica entre materia y espíritu. El resultado es que el hombre posee la facultad de entender(se) e interpretar(se) sin necesidad de mediaciones, pues el sentido del universo se traslada de lo transcendente a lo inmanente. Así lo reconoce Fray Martín de Córdoba en su Compendio de la Fortuna (1440-1453), capítulo XIII, al afirmar que el individuo adquiere dos tipos de bienes: aquellos que son de "graçia», y provienen del «amor divinal», y los que «puede alcançar por su propia naturaleza, e estos son bienes de fortuna, que no exçeden nuestra facultad".

En conexión con lo anterior, el dinamismo económico de las sociedades bajomedievales favoreció el cultivo de una nueva concepción de la identidad personal, alejada del colectivismo, pues como afirma Georges Duby:

impulsó las iniciativas personales, distendiendo las antiguas obligaciones....favoreció por todas partes las esperanzas de promoción individual y una sensación turbadora de progreso se grabó en las conciencias. ${ }^{2}$

En este contexto surge una controversia, dirigida por los más conspicuos moralistas, que afectará profundamente al intelectual, pues se centra en la confrontación entre la utilitas (noción arraigada en el ideario colectivista del sistema feudal), y la commoditas (vivencia privada del ocio). Por una parte se pro-

I Vid. CheVAlIER, MAXIME (1976): Lectura y lectores en la España del siglo XVI y XVII, Madrid, Turner; Zumthor, PAul (1987): La lettre et la voix: de la littérature médiévale, París, Seuil; DEYERMOND, ALAN (1988): «La literatura oral en la transición de la Edad Media al Renacimiento", Edad de Oro, VII, pp. 21-32; BIRGE, EVELYN (1994): «Romans, dir et contar: reflexions sur la performance des romans médiévaux», Cahiers de Littérature Orale, 36, pp. 35-63. Para ejemplos de los vínculos entre lectura oral y obras impresas, vid. GILMAN, STEPHEN (1984): «Entonación y motivación en La Celestina», Homenaje a Horst Baader, ed. por Frauke Gewecke, Barcelona, Hogar del Libro, pp. 29-36.

2 (1978): Hombres y estructuras en la Edad Media, Madrid, Siglo XXI, p. 264. 
paga el culto al ingenium, a la imaginación, a la expansión de la mente y del cuerpo como exponente de una perspectiva sensualista en auge; por otra, los perjuicios de índole religiosa sirven de contrapunto a esa exaltación de lo material. En tal disyuntiva, que los propios autores trasladarán a la escritura, cabe interpretar la tensión del discurso literario y la incidencia del acto de recepción en la dinámica creativa.

Las posibilidades de realización personal, en una sociedad más abierta como la descrita, permiten esta dualidad, asociada, incluso, a la edad, hasta el punto que, según Georges Duby ${ }^{3}$, crecen antagonismos hasta el momento desconocidos, como el conflicto generacional: los jovvenes se decantan por una opción progresista, vertical de la estructura comunitaria, prestando atención al entorno de lo real (estudiantes, caballeros, hijos de rentistas, etc.); los de edad madura se sienten más próximos a los modelos de conducta tradicionales.

La literatura refleja esta polaridad de actitudes a través de la contraposición entre lo poético (como parte del marginalia retórico) y el contenido transcendente: mientras aquél pertenece al dominio de las estrategias ingeniosas de la elocutio, sustentador del otium y de lo espiritualmente reprobable, éste es propio de una formación sólidamente establecida con la autoridad otorgada por el pasado. Los autores reconocen en su obra esta dicotomía, reflejada en su evolución personal, desde una disposición que va desde el simple reconocimiento a la inquietud cuando no al sincero arrepentimiento. Rodrigo Alcayde del Castillo, en su Spejo de la vida humana (1491), recuerda cómo su madre le aconsejaba estudiar la ley divina y olvidar los romances y narraciones, ya que éstos sólo atraen «mayormente a los mancebos por respecto de las fictiones y fábulas»; Juan de Mena, en las Coplas contra los pecados mortales (h.1453-1456) recomienda: «Usemos de los poemas/tomando dellos lo bueno,/ mas fuyan de nuestro seno/las sus fabulosas themas;/sus fiçiones y problemas/desechemos como espinas»; Diego de San Pedro, en Desprecio de la fortuna (1506), se lamenta de sus piezas escritas en la «liviandad de la edad»: «hasta aquí con obras vanas/y en escrituras livianas/siempre anduvo [mi seso] desterrado».

Los moralistas contextualizan dicha prevención en sus ataques a la vertiente sensualista de la cultura imperante, con manifestaciones tan claras como las de Pedro de Veragüe en su Espejo de dotrina (f.s.XIV): "Voluntad deves vençer/en gustar, ver e oler;/mas bien oír e [tanner]/buenas cosas» (estrofa 75). Más explícito es el Obispo Alonso de Cartagena, en una carta de 1487, a Fernán Pérez de Guzmán, recriminándolo en los siguientes términos:

3 Ibid. 
veo en vos no menos loable que en vuestra juventud o en la viril edad e aun algund tanto provecta, vos veía occupar en cuestiones e fazer vuestros dulzes metros e ritimos, que coplas llamamos, de diversas materias, mas eran de cosas humanas aunque estudiosas e buenas, pero agora acordades passar a lo devino e devoto, que a todo lo humano transcende, scriviendo por vuestra suave metrificatura himnos e oraciones e otras contemplaciones pertenescientes a consideración del culto divino.

Al margen de este debate -que de un modo u otro perdurará en el siglo $\mathrm{XVI}-$, la paulatina entronización del deleite formal como eje de la producción artística supuso un salto cualitativo notable en el criterio retórico, al sustituir la concepción mimética del arte -de origen aristotélico- por la doctrina horaciana cuyo núcleo es el conocido verso: «Non satis es pulchra esse poemata; dulcia sunto". La grandeza de lo estético se desplaza hacia su capacidad de estimular la sensibilidad del auditorio, en primer lugar, y, posteriormente, la totalidad del componente sensible y cognitivo. No es extraño que Enrique de Villena, en su Exposición del soneto de Petrarca, loe al gran poeta por su «deseo sitibundo de obtener plazer e fortuna de la plática poetal».

La consecuencia es que los textos reflejan la consolidación del universo ficticio, como espacio autónomo, en el que el autor desvela sus instrumentos y el lector se siente transportado por lo que Elena Artaza describe como «abismos casi infinitos por la mágica solicitación de la dulzura literaria» ${ }^{4}$.

Esta voluptuosidad, presente en la obsesión lectora tal como se explicita en numerosas obras que comentaré más tarde, alcanza su máxima expresión en los géneros narrativos, al tratarse de un discurso que se ajusta fielmente al horizonte de expectativas de las nuevas clases dominantes urbanas. En el paso del símbolo al signo - en terminología de Julia Kristeva ${ }^{5}$ - el intelecto personal puede por sí mismo acceder al sentido, al procedimiento semiótico, sin necesidad de mediaciones didácticas o religiosas. El roman, a diferencia del discurso épico, difunde un tipo de comunicación, a través de la lectura individual, privada, que favorece la ilusión realista (Horacio ya lo constataba, considerando que el relato oral, propio de la epopeya, difuminaba la percepción imaginativa). De este modo, si las gestas y romances medievales proyectaban la esfera volitiva de su auditorio - según indica Northrop Frye ${ }^{6}$ - , las nuevas formas novelescas propug-

4 (1988): El «ars narrandi» en el siglo XVI español, Bilbao, Universidad de Deusto, p. 119.

5 (1981): El texto de la novela, Barcelona, Lumen.

- (1980): La escritura profana. Un estudio sobre la estructura del romance, Barcelona, Monte Ávila, pp. 49 y ss. 
nan la no-disyunción —en terminología de G. Lukacs ㄱ-, es decir, su emancipación respecto a los ideales del destinatario. $\mathrm{B} \mathrm{W}$. Ife analiza los vínculos entre la prosa novelesca y los hábitos surgidos tras la consolidación de la imprenta:

La utilización de la prosa como vehículo para la literatura creativa contribuyó a crear una generación de lectores que se expuso a la ficción con una inmediatez sin precedentes. En un ambiente de silencio y soledad, recreaban para sí mismos pensamientos y fantasías de otros en un lenguaje parecido al suyo propio. ${ }^{8}$

El texto se individualiza, cobra autonomía, y es ficción, por lo que supone la narrativización de unos valores. La llamada «distancia estética» ${ }^{9}$ favorece el proceso de ficcionalidad, en el sentido que le otorga Walter Mignolo ${ }^{10}$, al considerar que la función-literatura crea el espacio ficcional de la enunciación por medio de sistemas lingüísticos y la semantización del contexto situacional. El lector toma conciencia del estatuto imaginario de la propuesta textual y le otorga el privilegio de insertarlo en un determinado discurso (el del género, por ejemplo) caracterizado por crear pautas de representación imaginaria, cuya verificación, siguiendo las teorías de los «mundos posibles», no está referida a las categorías de lo real sino a las establecidas por su propio código "

La conciencia de ficcionalidad aporta importantes consecuencias en el terreno de la competencia literaria, sobre todo en una época en la que las formas novedosas de la prosa novelesca están definiendo sus mecanismos genéricos, y fomentan una tendencia autoanalítica y metacognitiva de las estrategias textuales. Lo que más me interesa resaltar aquí es el aspecto sustentado sobre el vínculo entre el discurso literario y la instancia de recepción, modelizada en torno al esquema ideológico burgués.

En el prólogo a la edición valenciana de 1531 del Espill de Jaume Roig, el autor anónimo realiza la siguiente apología sobre la labor de los creadores de palabras y de historias:

La major y millor policia y més ingeniosa indústria que los fecundes oradors y laureats poetes acostumen y deven usar...si és ornar,

7 (1971): Teoria de la novela, Barcelona, Fundamentos.

8 (1992): Lecrura y ficción en el Siglo de Oro. Las razones de la picaresca, Barcelona, Crítica, p. 17.

9 Vid. Haidu, P. (1978): «Au début du roman», Poetique, 36, pp. 437-450.

10 (1981): «Semantización de la ficción literaria», Dispositio, V-VI, 15-16, pp. 85-127.

$"$ Vid. Pavel, T. (1986): Univers de la fiction, París, Seuil; Albadalejo,Tomás (1992): Semántica de la narración. La ficción realista, Madrid, Taurus. 
guamir y ataviar les composicions y fabriques que de la generació de sus fertils ingenis y conceptes, ab vigils treballs y contínues imaginacions, pululant y florint al vulgo per satiar y mantenir los vius enteniments presenten.

La ficción, expresada según una modalidad específica - determinada por los fundamentos narrativos-, transmitida en circunstancias concretas - por medios que potencian la privaticidad frente al colectivismo de la sociedad rural-, crea un universo significativo que recrea su estatuto imaginario, alejado de los mecanismos de la realidad, en un distanciamiento estético que es en sí mismo sintomático. Su función primordial será señalar vías de acceso a los «mundos ficcionales» desde el entorno vivencial, y ello como exponente del acto de lectura. Francisco Delicado, en el prólogo a la Lozana andaluza (1528), ya intuía esa atracción que arrastra al lector de relatos: "por este retrato sabrán muchas cosas que deseaban ver y oír, estándose cada uno en su patria, que cierto es una grande felicidad no estimada». En la «Dedicatoria» añade cómo espera conseguirlo, en una perfecta síntesis de lo que será la noción de verosimilitud: «mi intención fue mezclar natura con bemol, pues los santos hombres por más saber, y otras veces por desenojarse, leían libros fabulosos y cogían entre las flores las mejores».

Los autores de un género tan popular en el siglo XV, como la «novela sentimental», incorporan esa demanda de ficción como una de las funciones-marco del relato en el proceso de transición textual entre la enunciación y el comienzo de la ficción. Juan de Flores, al inicio del Triunfo de Amor (1471-1485), escribe una carta a las «enamoradas dueñas» en la que manifiesta: «me conviene ir a muy apartadas tierras a traher nuevas de las grandes cosas que acaescen en cabo del mundo», de donde «vengo acompañado de novelas, por que por oírlas os gozéis», por lo que exige a sus lectoras que «así yo, por mucho que me llore, si vosotras como Dios no guarescéis mi mal, mi trabajo será en vano, aunque más en cabo del mundo me destierre a buscar la vida».

El ingenio de estas aseveraciones, en las que el autor desvela su conversión en narrador $y$, por ende, la de todo el entramado de la comunicación literaria, es uno de los rasgos que mejor definen la prosa de la época. Con ello se revela no sólo la variedad de las innovaciones técnicas, como resalta Alan Deyermond ${ }^{12}$, sino también la voluntad de explicitar un cambio en el proceso de recepción y su consecuente reflejo en el texto como producto significante. El escritor, poeta, orador, aparece loado por su capacidad imaginativa, su lógica creadora y su

12 (1995): «Las innovaciones narrativas en el reinado de los Reyes Católicos», Revista de literatura medieval, VII, pp. 93-105. 
facilidad para construir tramas, conflictos y situaciones que estimulan la fantasía humana, arrebatándole de las cada vez más acuciantes necesidades socioeconómicas. El autor valenciano Jaume Gassull, en su obra maestra Lo somni de Joan Joan (1497) ofrece una buena muestra de tal disposición:

\author{
Perquè los tests resten hi gloses \\ en aquest món, \\ per avivar d'aquells qui y són \\ l'enteniment; \\ hi.ls que y vendran, més fâcilment \\ tinguen raho, \\ avinenten hi saó \\ d'aprofitar-se'n; \\ hi perquË més puguen alta-se'n, \\ hi discernir \\ les flors dels fruyts, hi prest collir \\ fruytes eletes \\ dels arbres bells que.ls grans poetes \\ han tresplantat \\ fingint de fals $y$ ab veritat \\ coses ben dites \\ han ordenat ab eloqüència \\ hi bell estil, \\ tant que.s conexen entre mil \\ d'aquells les letres, \\ puix afalaguen tant les metres \\ nostres orelles.....
}

La importancia del lector como instancia del discurso se refleja en la transición hacia un tipo de actitud receptiva distinta a la planteada por los textos medievales. De este modo asistimos al paso de la obra-tratado, tipificada por su voluntad de actuar directamente sobre un destinatario homogéneo en torno a unos valores colectivos (morales, ideológicos, etc.), a la obra dirigida a un público heterogéneo, que se aleja de la función pragmático-perfectiva optando por una ambigüedad como modo de expresar la opacidad formal típica de la categoría literaria. Los autores confiesan escribir para una lector in fabula, no necesariamente uniforme en su imago mundi, pero sí con unas condiciones sociológicas, de formación, que les lleva a aproximarse al texto buscando algo más -o diferente- del mero didactismo.

El fenómeno literario está adquiriendo una nueva dimensión, superando los prejuicios y las limitaciones caracteriológicas impuestas por el reducido 
grupo de eruditos medievales, hasta convertirse en una vivencia cotidiana, integrada en el entorno público del ciudadano (la imprenta contribuy6 a ello), pero también en su res privata. Así lo manifiesta el Marqués de Santillana, en su Prohemio e carta, indicando que la ciencia poética es «a todo linage e especies de gentes». En el Corbacho (1466), Alfonso Martínez de Toledo explicita esa transición entre la estructura del tractatus y la forma abierta a todo tipo de lectores (afirmaciones que recuerdan las palabras de Juan Ruiz en el Libro de buen amor); así, primero se ajusta a la ortodoxia moralizante:

propuse de fazer un compendio breve en romance para información algund tanto de aquellos que les pluguiere leerlo, e leído retenerlo, e retenido, por obra ponerlo.

Más tarde reconoce que su obra cuenta con un lector más variado que, según sus circunstancias, entenderá la obra de una manera u otra; el texto amplía su virtualidad expresiva a la par que se convierte en síntoma de un horizonte de expectativas determinado por la heterogeneidad del receptor:

si algo fuere, segund sus viçios e mal vevir que oy se usa, de algunos o algunas aquí dicho e escrito, non sea notado a detracción, ni querer afear, maldezir e fablar, nin disfamar, salvo de aquellos e aquellas en quien los tales vicios o males fueron fallados exerçitar e usar e continuar, los buenos e buenas en sus virtudes loando e aprovando; que si el mal no fuese sentido, el bien non sería conoscido.

Jaume Roig, en Espill, logra un perfecto equilibrio entre las dos dimensiones del individuo urbano: por una parte dice dirigir la obra a su sobrino, Baltasar Bou, a modo de pieza doctrinal siguiendo el tópico del puer-senex; por otra, pretende sintonizar con otro tipo de lector cuya interaccion sobre la historia propuesta dependerá de sus condicionamientos: «Segons son gust/e sa sabor/ cascun lector/prest trobarà/lo que volrà».

El texto integra, en conclusión, un modelo de discurso asentado sobre unas imposiciones comunicativas a las que el autor debe atender. Su valor estético, su simbolismo - como proceso semiótico de la forma literaria- viene garantizado por la percepción, según teoría de Jan Mukarovsky ${ }^{13}$, de que el texto propone un gesto semántico más allá de la interpretación literal, exigiendo un esfuerzo interpretativo por parte del destinatario. Así se comprenden palabras como las de Diego de San Pedro en su Sermón (h. 1485) al considerar a

13 (1977): Escritos de estética y semiótica del arte, Barcelona, Gustavo Gili. 
los lectores no sólo determinantes implícitos de la organización textual, en terminología de Wolfang Iser ${ }^{14}$, sino que propone una verdadera retórica de la dialéctica creación/lectura:

Para que toda materia sea bien entendida y notada, conviene que el razonamiento del que dize sea conforme a la condición del que lo oye.

Estas palabras revelan cómo los autores de la época atienden al constituyente comunicativo pragmático, en particular a las estrategias de la ficción, tanto en el plano de la fábula como en las formas del discurso, para captar la atención del receptor. No se trata sólo de un planteamiento estructuralista tendente a fijar la sintaxis de la organización textual para conseguir un determinado efecto en la pragmática comunicativa, sino de evidenciar la distancia del artefacto estético respecto a la experiencia real del lector, forjando una competencia en torno a nuevos valores que superen la controversia medieval entre el «arte pedagógico» y el «arte meretriz».

Esta disposición nos sitúa ante nociones doctrinales de primer orden en su vertiente más pragmática: la dualidad res/verba, su implicación en los debates retóricos sobre la dificultad de la forma poética y, en definitiva, una controversia teórica seguida de cerca — cuando no protagonizada- por los escritores, cuya directriz axial es la actitud del lector en las comunidades urbanas y cómo la ficción textual debe atender a nuevas expectativas desconocidas en la producción y transmisión de los textos medievales.

En efecto, la lectura silente favorece lo que Marshall McLuhan ${ }^{15}$ denomino «la falacia del sentido», esto es, la tendencia al análisis individual de un público, convertido ya en «función-lector» (en correspondencia a la «función-autor» de la que habla Michael Foucault ${ }^{16}$ ), que, como anticipé al inicio del artículo, se siente impulsado y capacitado para interpretar el contenido más allá de la «ruda letra». Pero, además, como afirma Elizabeth Eisenstein, un público de lectores «era más atomista e individualista que uno de oyentes» ${ }^{17}$, con lo que ello implica en las relaciones entre el texto y el acto de recepción.

La dificultad conceptista, defendida por los tratados poéticos del siglo $\mathrm{XV}$, es, en su origen, la constatación de unas nuevas condiciones en la comunicación literaria, de manera que el autor exige explícitamente al lector un es-

is (1987): El acto de leer, Madrid, Taurus.

15 (1993): La galaxia Gutenberg. Génesis del «Homo typographicus», Barcelona, Galaxia Gutenberg-Círculo de lectores.

16 (1996): De lenguaje y literatura, Barcelona, Paidós.

17 (1994): La revolución de la imprenta en la Edad Moderna europea, Madrid, Akal, p. 97. 
fuerzo analítico que cierre el ciclo del proceso creativo ${ }^{18}$. La dualidad res/ver$b a$ actualiza una cualidad inherente a toda propuesta textual: la fábula es sólo un síntoma, exponente externo de una materia a la que el destinatario - seleccionado por la propia retórica de la escritura- debe acceder para constatar su propia condición de lector (con todas las implicaciones sociologicas e ideologicas que ello conlleva). El texto se ofrece como una imagen metonímica, como un gesto dirigido a la individualidad, en su aproximación a la letra impresa, como resume la advertencia que el autor anónimo de Espill de la vida religiosa (1515) realiza a sus lectores:

Emperd nota, llegidor, que encara que lo present llibre sia poquet en quantitat, empero es molt gran en virtut.

Enrique de Villena, en el prólogo a los Doce trabajos de Hércules (1417), es más explícito al declarar el sentido compositivo del libro - con sus planos alegórico y tropológico-, y admitiendo que:

aquí non estén deduzidos específicamente cada uno de los nombrados estados por cada un trabajo con sus diferençias e variedades de casos, sinon impliçitamente e sumaria por graçia de brevedat, empero por lo que aquí será dicho i exemplificado avrés manera e artifiçio para deduzir e aplicar los dichos trabajos.

Esto supone, por supuesto, que la obra «se fazía e enderesçava para vos... que sodes entendido e avisto, siquier ingenioso, e sabrés no dubdo explicar lo que implíçitamente es proseguido».

La extensión del público lector, atento a la latencia semántica del texto impreso, genera una clara división social (con visos clasistas muy evidentes), no sólo entre grupos rurales y urbanos, sino también entre lo que Elizabeth Eisenstein caracteriza como el universo de los oyentes y el de los lectores. La nueva élite intelectual organiza sus rasgos identificativos en torno a la superioridad otorgada por la capacidad de acceder a las «escuridades e cerramientos» (Marqués de Santillana, Prohemio e carta), con las consecuencias políticas y religiosas que tendrá esta división en el siglo XVI. Alfonso de la Torre, en su Visión deleytable (h. 1440), mostraba su admiración por ese selecto grupo de elegidos llamados a formalizar un nuevo concepto de la cultura: «E munxo es de alabar aquel que con inquirición no mediocre, la profunditat delas tales cosas [el sentido de la ciencia]

18 Para una historia de esta doctrina estética en la literatura espanola, Garcla Berrto, ANTONIO (1968): Esparia e Italia ante el conceptismo, Murcia, Universidad de Murcia. 
trabaia de conocer». Así aconseja Rodrigo Alcayde del Castillo, en el prólogo a Spejo de la vida humana: «e mientra las partes de fuera se da a tu juicio, el intellecto interior, ahunque flaco y rudo, no duerma».

En el dominio de la ficción literaria cobra plena vigencia la idea de que el destinatario debe hacer gala «de sano entender», porque lo que identifica el componente formal artístico de lo poético es su especial modo de significar, en el que el receptor ha de enfrentarse a la dialéctica res/verba, hasta alcanzar el sentido último del texto. Así, la literatura aparece como una condensación que exige, como indicaba Baltasar de Romaní — traductor de Ausiàs March al castellano, en 1531—, «trabajar d'entender sus difficultades», por lo cual el acto de recepción representa la culminación del proceso de ficcionalidad, inscribiéndose como parte integrante del sistema de creación. El autor cuenta con los recursos de la retórica y con un lector a quien dirige su pieza, no sólo como factor condicionante de la producción, sino como una función a quien exige -y, por ello, distingue - la descodificación de la verba poética. Joan Roís de Corella, en Lo juí de París (h.1471), exponía esa peculiaridad sintética de la expresión: «a l'expondre de les poesies, no és mester totes les particularitats se declaren; mas hasta la fi per la qual se diu espondre».

Los autores de novelas sentimentales, quizá los primeros que de una manera voluntaria escribían para un público concreto, son los que mejor detallan el estrecho vínculo entre la práctica literaria, como una retórica de la fícción que desarrolla el ars y el ingenium, y el horizonte de expectativas que se plasma en un público plenamente identificado (que también puede ser auditorio, en la compleja dialéctica lectura/oralidad característica del período ${ }^{19}$ ). Juan Rodríguez del Padrón, en el Siervo libre de amor, se involucra a sí mismo como sujeto del enunciado (actitud frecuente entre los narradores de la época), describiéndose «trayendo fiçiones», con el fin de «aprovechar y venir a ti en plazer con las fablas que quieren seguir lo que naturaleza no puede sufrir aprovechar con el seso alegórico que trahe consigo la ruda letra», por lo que, continúa indicando al lector, «si requieren de sano entender, armas te dizen contra el amor». Pero es Diego de san Pedro quien llega más lejos al buscar la complicidad de su público - femenino y cortesano-, aconsejándole que no se quede en la «corteza», superando los límites del dictum. Así lo afirma en el prólogo al Tractado de amores de Arnalte y Lucenda (1491):

vosotras, señoras, rescevid [en] servicio no lo que con rudeza en el dezir publico, mas lo que por falta en el callar encub[r]o, de manera que 
si los motes la obra sufriere, la voluntad las gracias resciba, agradesciendo no lo que [dixere] mas lo que dezir quise.

Se trata de una exigencia que afecta al discurso artístico de la Baja Edad Media, como reconoce Philippe Branstein en su análisis de la pintura flamenca del período:

Ante la superficie lisa del cuadro, es a la mirada del espectador a la que le corresponde dar con la clave, recomponer al individuo y devolverle su secreto. ${ }^{20}$

En afirmaciones como las de Diego de San Pedro se reconoce una crítica implícita al exceso formalista en el que incurrían los escritores sólo atentos a las indicaciones sobre el ornatus de los tratados retóricos. Rodrigo Alcayde del Castillo, en el capítulo XXXVIII-Libro I, del Spejo de la vida humana, considera negativa la tendencia hedonista de los que hablan «para inclinar los coraçones, mas para vençerlos», 0 , lo que es lo mismo, el dirigirse únicamente a lo afectivo, sin que ello suponga una vía de acceso a la formación intelectual; esta preferencia - continúa - ha favorecido una cierta superficialidad interpretativa, pues el lector se habitúa a «tomar las foias por el fruto y se apasciente de fumo, pensándose llegar al fuego».

Lo cierto es que ya desde las preceptivas de la «Gaya ciencia», existía una preocupación por el proceso comunicativo en su relación con la integridad de la fábula y con el sentido figurado de la ficción (Enrique de Villena, en su Arte de trovar, establecía la prioridad de una normativa para poder «transfundir en los oidores de vuestras obras las esçelentes invençiones que natura ministra a la serenidat de vuestro ingenion). Sobre esta nueva disposición se proyecta la imagen de un tipo de lector que ya no es una entelequia, sino una intancia modelizadora del discurso, por lo que el escritor es plenamente consciente -incluso con una cierta prevención- de lo que implica el acto de lectura, y, como Fernando de Rojas indica en el prólogo a la edición de 1502 de $L a$ Celestina, cuenta con que cada uno «dé sentencia sobre ella a sabor de su voluntad».

Ante esta constatación los textos de la época organizan su sistema semántico incorporando la tensión generada por la dialéctica entre el autor-narrador, la historia en los márgenes de la realidad-ficción, y la presencia latente del re-

20 "Aproximaciones a la intimidad, siglos XIV y XV», en ArIEs, PHILIPPE y DUby, Georges coord. (1991): Historia de la vida privada. El individuo en la época feudal, Madrid, Taurus, pp. 201-311, cita pp. 250-251. 
ceptor. De este modo, el texto difunde una imagen contradictoria, en la que los signos de distanciamiento estético son simultáneos a los guiños de complicidad con la experiencia de lo real; la homogeneidad en las referencias ideológicas se pretende hacer compatible con la dispersión interpretativa. Estas tentativas en el ámbito de la creación literaria explican el temor a las consecuencias del acto interpretativo, de naturaleza heterogénea, que pueden llegar a desvirtuar la voluntad primigenia del autor (ya desprovisto del dominio absoluto sobre la materia narrada). Este es el argumento esgrimido por Pedro Ximénez de Urrea quien, en su Penitencia de amor (1514), se muestra temeroso ante esa posibilidad, lo que le lleva a concluir que: «No querría que esta obrezilla fuesse muy vista, porque de contino estas cosas atraen juizio». Diego de San Pedro, en Desprecio de la fortuna (1506), se queja amargamente de los sinsabores que le han reportado las lecturas malintencionadas de su Cárcel de amor:

\section{Y como la obra tal no tuvo en leerse calma, he sentido por mi mal cuán enemiga mortal fue la lengua para el alma.}

En consecuencia, en los prólogos y advertencias preliminares, los autores manifiestan su convencimiento de que el texto es una unidad inalterable en su composición significativa, si bien susceptible de ser mejorado a través de la lectura (tributo a la oralidad - aún vigente- en la que la lectura colectiva convierte al texto en un «hacerse» continuado). Así, Francisco Delicado exige para su Lozana andaluza «que ninguno quite ni añada palabra, ni razón, ni lenguaje» ${ }^{21}$. De nuevo surge la paradoja característica de las relaciones autor-texto-destinatario: por una parte, la evidencia de que la lectura silente, individual, enriquecerá al texto, aportándole una virtualidad interpretativa más allá de la simple finalidad lúdica; por otra, el temor a perder el control sobre el sentido del discurso, al estar la obra sometida al juicio -incluso al arbitrio económico - de un público variado, que la somete a debate, la utiliza como tema de conversación, pasando a ser el núcleo de un nuevo enfoque de las relaciones sociales (así, en las tertulias, academias, o como producto de la moda en-

21 Es evidente que algunas de estas quejas iban dirigidas a las manipulaciones de los editores, como un capítulo más de la historia legislativa en torno a la propiedad intelectual. Para una síntesis del problema, con especial mención de La Celestina, vid. BoTTA, PATRIZIA (1997): «El texto en movimiento (De La Celestina de palacio a La Celestina posterior)», en Cinco siglos de Celestina: aportaciones interpretativas, BELTRÁN, RAFAEL y CANET, JOSÉ LUIS ed., Valencia, Universitat de Valencia, pp. 135-159. 
tre las clases urbanas ${ }^{22}$ ). Jaume Roig, en el prefacio del Espill, refleja esta aparente contradicción pidiendo al lector:

\begin{tabular}{|c|c|}
\hline & Que a caplleuta \\
\hline suplic, exorte & la que reporte \\
\hline e tinc emprès & sia remès; \\
\hline $\begin{array}{l}\text { no pas scapçat, } \\
\text { per veedós }\end{array}$ & $\begin{array}{l}\text { partit, trencat, } \\
\text { e miradós }\end{array}$ \\
\hline rot ni squinçat; & mas sols pinçat \\
\hline e corregit, & llimat, llegit \\
\hline $\begin{array}{l}\text { o bé scoltat, } \\
\text { benignament. }\end{array}$ & sia acceptat \\
\hline
\end{tabular}

Anselm Turmeda, en el Llibre de bons amonestaments (1398), parece admitir una cierta autonomía del texto, la que le otorga el propio acto interpretativo, que permite multiplicar su virtualidad significativa más allá de las imposiciones del autor:
$\mathrm{Tu}$, llegidor qui llegiràs
lo meu llibre, si hi veuràs
algun bon dit, aquest prendràs,
e l'atre lleixa.
Llegidor, prec-te humilment
Si hi trobes negun falliment
Que per tu ivarçosament
Esmenat sia.

Muy próxima a esta vocación constructiva del proceso de lectura, en correspondencia con la función diseminadora del destinatario heterogéneo, está la «Peroración hecha por el muy discreto y grande orador el bachiller Villoslada», incluida en la edición de la Repetición de amores (1497) de Juan Ramírez de Lucena, al aconsejar que se tenga «en poco las vanas reprehensiones del pueblo para comenzar [la obra] y en mucho para se limar desvelado».

En la transposición del acto enunciativo al enunciado de ficción, el receptor se incorpora como función productora de los mecanismos de ficcionalidad, como lo revelan las estrategias creativas de los autores. En esta línea, uno de los recursos más comunes es responsabilizar al público, a través de su demanda, del esfuerzo imaginativo desarrolado, implicándolo en una historia que

22 Vid. VELLON, JAVIER, «La oralidad en la cultura burguesa: literatura y tertulias femeninas en la Baja Edad Media» (en prensa). 
afecta, incluso, al origen de la propia fábula. Juan de Flores, en el prólogo a Triunfo de Amor, en su diálogo directo con el público femenino afirma que cuando emprende la labor narrativa debe ir a lejanos países, «y quando de año a año vengo con unas nuevas, luego me mandáis ensillar y acaminar por otras». A la vez que asume su conversión en narrador (tránsito de sumo interés en las diversas variantes propuestas por los novelistas del período ${ }^{23}$ ), exige que el lector pase a ser el correlato ficticio del relator de la historia:

y así yo, por mucho que llore, si vosotras como Dios no guarescéis mi mal, mi trabajo será en vano, aunque más en cabo del mundo me destierre a buscar la vida.

El mismo autor, en su Historia de Grisel y Mirabella (1495?), le confiesa «a su amiga» que «sin esfuerzo vuestro yo no osara atreverme a tan loco ensayo». Al margen de la concesión a la laudatio de estas palabras, el novelista utiliza este apoyo retórico para presentarse como un simple transcriptor de los deseos de un receptor individualizado:

Pues yo desto solamente so escribano; que por la comunicación de vuestra causa he trabajado por hacer alguna parte de las obras de vuestra discreción, para me aprovechar en esta necesidad dellas.

En ocasiones, la petición del lector es el motivo de que la obra vea la luz, responsabilizándolo, así, de su génesis y difusión. Tal es el caso del escritor valenciano de mediados del siglo XV Francesc Carrós Pardo de la Casta, quien en su tratado amoroso Regoneixença $i$ moral consideració contra les persuasions, vicis i forces de amor imputa a «vostra mercè» que la «simple obreta» haya sido algo más de lo que eran unos apuntes «sols per a mon descans», cuyo fin era «posar-hi silenci, fugir a la llum»; frente a ello, confiesa que ha debido rendirse al empeño de su destinatario, que desea la pieza «como si en ella algun estil o tresor de saber trobar-se pogués». Las estrategias de la enunciación, como se ve, permiten contextualizar ficciones que, a su vez, desde la instancia literaria proclaman autoloanzas muy perceptibles.

La inclusión del receptor como función generadora del relato llega a modelizar no sólo el origen del acto imaginativo, sino también la propia estructura y los procedimientos narrativos, hasta el punto de situarse como referencia misma de la fábula, por encima del propio narrador. Es ilustrativo el ejemplo

23 Vid. DEYERMOND, ALAN: «Las innovaciones narrativas...», art. cit. 
de la Triste deleitación (h.1460), de Gómez Manrique, en la que la verdad poética se subordina a una supuesta realidad de la que son testigos los lectores. Efectivamente, el escritor anuncia que no desea concluir la historia amorosa de los protagonistas, al tratarse de una historia real, y si la manipulara sus lectores le reprocharían, pese a que su deseo inicial era cumplir las normas del género y que «el enamorado» y «la doncella» lograran «ajuntamiento de gran amor»:

Mas por quanto asta donde me dexé el scritura mía verdadera se mostrava, no quise adelante proçeder.

Asistimos, en conclusión, a la época inicial de los «leyentes y bivientes», como denominaba Alfonso Martínez de Toledo -en su Atalaya de las Corónicas (h.1443) - a los consumidores de la letra, cada vez más impresa, con lo que ello comporta en cuanto a hábitos y modos de aproximación al texto. La adicción a la novedad, al análisis, a la aventura, son consecuencias de este entretenimiento que empezaba a gozar de una gran difusión en los núcleos urbanos, y que estaba llamado a transformar las costumbres sociales entre las clases medias de las ciudades. Así lo reconoce Margit Frenk en su ejemplar estudio sobre el nuevo lector:

En la lectura solitaria y silenciosa, el cuerpo del individuo ha venido a suplantar al cuerpo social que escuchaba, viviéndolas colectivamente, las lecturas en voz alta. ${ }^{24}$

De este modo la recepción se convierte en parte integrante del proceso creativo; en primer término como fuente de la imaginación, como estímulo literario, no en vano Fernando de Rojas se definía como un lector empedernido, con la mentalidad abstracta y racionalmente ordenada que McLuhan consideraba propia de los nuevos consumidores de la letra impresa, capaces de extraer de una obra diferentes niveles de contenido, $y$, así, en el prefacio «El autor a un su amigo", que inicia la primera edición de su obra maestra, se refiere a la pieza del autor desconocido en los siguientes términos:

leflo tres o quatro vezes. E tantas quantas más lo leía, tanto más necessidad me ponía de releerlo e tanto más me agradava y en su processo nuevas sentencias sentía. Vi, no sólo ser dulce en su principal

${ }^{24}$ (1997) Entre la voz y el silencio (La lectura en tiempos de Cervantes), Alcalá de Henares, Biblioteca de Estudios Cervantinos, p. 84. 
historia o ficción toda junta; pero aun de algunas sus particularidades salían deleitables fontezicas de filosofía, de otros agradables donaires...

La lectura, a lo largo de la novelística del siglo XVI, entrará a formar parte del discurso, bien a través de la fijación de una estructura comunicativa como marco de la ficción (es el caso del género epistolar, tan enaltecido por los humanistas como contexto de la ficcionalización), bien, en su elaboración más madura, como referente justificativo de la propia existencia de la fábula: se trata, en último término, de novelizar el efecto de pasar «las noches leyendo de claro en claro, y los días de turbio en turbio». 